\title{
The ageing effect on the bioaccessibility and fractionation of arsenic in soils from China
}

\author{
Xiang-Yu Tang a,b, Yong-Guan Zhu ${ }^{\text {a,*, }}$, Xiao-Quan Shan ${ }^{\text {a }}$, \\ Ron McLaren ${ }^{c}$, Jing Duan ${ }^{a}$ \\ a Department of Soil Environmental Science/State Key Laboratory of Environmental Chemistry and Ecotoxicology, Research Center for \\ Eco-Environmental Sciences, The Chinese Academy of Sciences, Beijing 100085, PR China \\ ${ }^{\mathrm{b}}$ National Institute for Agro-Environmental Sciences, Tsukuba, Ibaraki 305-8604, Japan \\ ${ }^{c}$ Soil and Physical Sciences Group, Agriculture and Life Sciences Division, P.O. Box 84, Lincoln University, Canterbury, New Zealand
}

Received 5 February 2006; received in revised form 8 July 2006; accepted 31 July 2006

Available online 11 September 2006

\begin{abstract}
Ingestion of contaminated soil has been recognized as an important exposure pathway of arsenic for humans, especially for children through outdoor hand-to-mouth activities. An improved sequential extraction procedure was employed in an attempt to reveal the relationship between bioaccessibility and fractionation of As in five soils from China. Arsenic bioaccessibility in acidic $(\approx \mathrm{pH} 4.5)$ soils reached approximately stable levels after a sharp decline within one week of ageing. In contrast, As bioaccessibility in higher pH $(>6.0)$ soils was found to be significantly higher and took two weeks of ageing to reach stable levels. The artificially added As was more labile than indigenous As. The main proportions of added As were found in the specifically sorbed and amorphous and poorly-crystalline hydrous $\mathrm{Fe} / \mathrm{Al}$ oxide-bound fractions. Correlation analysis shows that the non-specifically and specifically sorbed As are likely to constitute the main proportion of bioaccessible soil As. The soil content of amorphous and crystalline Fe/Al oxides and soil pH appear to be the key factors controlling, not only the time needed to reach a steady state, but also the magnitude of the bioaccessibility of As added to the soils.
\end{abstract}

(C) 2006 Elsevier Ltd. All rights reserved.

Keywords: Arsenic; Ageing process; In vitro test; Sequential extraction procedure

\section{Introduction}

Soil ingestion is regarded as an important human exposure pathway of contaminants, especially for children through outdoor hand-to-mouth activities. The daily amount of soil ingestion has been estimated to be in the range of $50-200 \mathrm{mg} \mathrm{d}^{-1}$ (Van Wijnen et al., 1990). Moreover, children have the ability to absorb higher proportions of metals through the digestive tract to reach systemic circulation than adults, which may make them subject to higher adverse health effects (Miller and Schricker, 1981;

\footnotetext{
* Corresponding author. Tel.: +86 106293 6940; Fax: +86 1062923563. E-mail address: ygzhu@rcees.ac.cn (Y.-G. Zhu).
}

Calabrese and Stanek, 1995). Arsenic contaminated soil has long been recognized as a threat to human health.

It has been recognized that soil contaminants are usually less than 100\% bioavailable (Rodriguez et al., 1999). Given the expense and time constraints associated with animal testing, much recent attention has been directed to the development of in vitro extraction tests that mimic the human digestion process. Such tests estimate bioaccessibility on the basis of the maximum amount of soil contaminant that is soluble in the digestive fluid, and is therefore available for intestinal absorption (Ruby et al., 1999).

The decreasing bioaccessibility of a metal to a given biological organism with increasing contact time with the soil is often termed "ageing", although the specific retention mechanisms responsible are not well understood. 
However, it is supposed that adsorption of cations and/or anions (e.g. lead, $\mathrm{Pb}^{2+}$; selenite, $\mathrm{SeO}_{3}^{2-}$ : selenate, $\mathrm{SeO}_{4}^{2-}$ ) on soil surfaces initially form outer-sphere complexes, followed by the formation of inner-surface complexes (Hayes and Leckie, 1986; Zhang and Sparks, 1990). Upon ageing, intraparticle surface diffusion of metal contaminants within micropores may result in reduced lability, and may also result in nucleation and surface precipitation (Ford and Sparks, 2000; Axe and Trivedi, 2002). These mechanisms appear to be reasonable explanations for the decreasing potential for contaminant release from polluted soil during the ageing process. However, such a general explanation may not be sufficient to account for variations in the bioaccessibility of soil As with ageing, which involves the partition of As among different soil components.

To the authors' knowledge, only a limited number of reports have focused on the effects of ageing on the bioaccessibility of As in soil and the underlying mechanisms involved. Yang et al. (2002) found that the bioaccessibility of arsenate added to soils was significantly reduced in some soils over time, and that the iron oxide content along with $\mathrm{pH}$ appeared to be the main soil factors controlling the steady-state bioaccessibility of arsenate. Fendorf et al. (2004) also reported that exchangeable As in two soil samples (as extracted with $1 \mathrm{M} \mathrm{MgSO}_{4}, \mathrm{pH} 7$ ), decreased with incubation time and was highly correlated with an exponential decline in the bioaccessibility of As. Another recent paper by Yang et al. (2005) showed that a significant portion of arsenite added to soils was oxidized to arsenate over six month's aerobic ageing, decreasing remarkably the bioaccessibility of As. However, in all these three studies, As bioaccessibility was determined using an artificial gastric phase only, without further assessment using an artificial small intestinal phase.

The objectives of this study were to investigate (i) the ageing effect on the bioaccessibility of As in five soils from China using a modified physiologically based in vitro test, and (ii) the availability of soil As fractions for intestinal absorption using a sequential extraction procedure As.
Such investigations could be crucial for assessing temporal variations in health risks at either new or historically Ascontaminated sites.

\section{Materials and methods}

\subsection{Soil preparation}

Five typical uncontaminated, non-cultivated soils were collected from sites throughout China in Changchun, Beijing, Nanjing, Yujiang, and Hainan. The soils were classified as a Cryi-Ustic Isohumosol (CC), a Hapli-Ustic Argosol (BJ), a Ferri-Udic Argosol (NJ), a Haplic-Udic Ferrosol (YJ), and a Rhodi-Udic Ferralosol (HN) (Cooperative Research Group on Chinese Soil Taxonomy, 2001). The soils were air-dried, ground, and passed through a $2 \mathrm{~mm}$ mesh sieve. Samples ( $400 \mathrm{~g}$ ) of each soil were spiked with $60 \mathrm{ml}$ of $\mathrm{Na}_{3} \mathrm{AsO}_{4}\left(600 \mathrm{mg} 1^{-1}\right.$ of As) solution to artificially increase the total As concentration in the soils by about $120 \mathrm{mg} \mathrm{kg}^{-1}$. The samples were then mixed thoroughly, and after being air-dried and homogenized again by sieving, $40 \mathrm{~g}$ subsamples were weighed into plastic cups. Double distilled water was added to the cups to adjust the soil moisture to $15 \%$ on a weekly basis to simulate field-like drying-wetting cycles. All soils were stored in the dark at $25^{\circ} \mathrm{C}$. At different times $(1,3,7,14,30,60$, and $120 \mathrm{~d})$ after the As addition, the samples were air dried, and then ground gently with a wooden spatula. Since it is usually assumed that only soil particles less than $0.25 \mathrm{~mm}$ in diameter adhere to the hands of children (Duggan et al., 1985), this soil fraction only $(<0.25 \mathrm{~mm})$ was used for both the in vitro extraction test and the sequential fractionation,. Some basic characteristics of the soils $(<0.25$ fraction $)$ including the background As concentrations are shown in Table 1.

\subsection{Characterization of soils}

Particle size composition of the $<0.25 \mathrm{~mm}$ soil fraction was analyzed with a laser particle size analyser (Mastersizer

Table 1

Selected physical and chemical properties of the experimental soils

\begin{tabular}{|c|c|c|c|c|c|c|}
\hline \multicolumn{2}{|l|}{ Soil } & $\mathrm{CC}$ & BJ & NJ & YJ & $\mathrm{HN}$ \\
\hline \multicolumn{2}{|l|}{$\mathrm{pH}\left(\mathrm{CaCl}_{2}\right)$} & 6.09 & 7.43 & 6.09 & 4.50 & 4.56 \\
\hline \multicolumn{2}{|l|}{$\mathrm{CaCO}_{3}\left(\mathrm{~g} \mathrm{~kg}^{-1}\right)$} & 8.75 & 36.88 & 7.88 & 4.38 & 2.38 \\
\hline \multicolumn{2}{|l|}{$\mathrm{OC}\left(\mathrm{g} \mathrm{kg}^{-1}\right)$} & 15.40 & 41.02 & 26.46 & 3.68 & 4.86 \\
\hline \multicolumn{2}{|l|}{$\mathrm{Fe}\left(\mathrm{g} \mathrm{kg}^{-1}\right)^{\mathrm{a}}$} & 2.47 & 1.14 & 2.91 & 2.79 & 2.70 \\
\hline \multicolumn{2}{|l|}{$\mathrm{Fe}\left(\mathrm{g} \mathrm{kg}^{-1}\right)^{\mathrm{b}}$} & 1.75 & 2.90 & 3.60 & 19.77 & 46.15 \\
\hline \multicolumn{2}{|l|}{$\mathrm{Al}\left(\mathrm{g} \mathrm{kg}^{-1}\right)^{\mathrm{a}}$} & 0.87 & 1.06 & 0.69 & 1.36 & 1.70 \\
\hline \multicolumn{2}{|l|}{$\operatorname{Mn}\left(\mathrm{g} \mathrm{kg}^{-1}\right)^{\mathrm{b}}$} & 0.00 & 0.01 & 0.00 & 0.06 & 0.32 \\
\hline \multicolumn{2}{|l|}{ As $\left(\mathrm{mg} \mathrm{kg}^{-1}\right)$} & 11.41 & 11.00 & 9.37 & 20.84 & 17.05 \\
\hline \multirow{3}{*}{$\begin{array}{l}\text { Particle size } \\
\quad \text { composition (\%) }\end{array}$} & Sand $(>0.05 \mathrm{~mm})$ & 5.1 & 5.1 & 4.0 & 0.9 & 3.0 \\
\hline & Silt $(0.002-0.05 \mathrm{~mm})$ & 82.2 & 77.3 & 88.1 & 58.8 & 64.3 \\
\hline & Clay $(<0.002 \mathrm{~mm})$ & 12.7 & 17.6 & 7.9 & 40.3 & 32.7 \\
\hline
\end{tabular}

${ }^{\mathrm{a}}$ and ${ }^{\mathrm{b}}$ represent amorphous and crystallised oxides, respectively. 
2000, Malvern Co., UK) after dispersion by adding $0.5 \mathrm{M}$ $\mathrm{NaOH}$ to the two most acidic soils ( $\mathrm{YJ}$ and $\mathrm{HN}$ ), and $0.5 \mathrm{M}$ sodium oxalate to the soils with $\mathrm{pH}$ values above 6.0 (CC, BJ, and $\mathrm{NJ})(\mathrm{Lu}, 2000)$. Soil $\mathrm{pH}$ was measured potentiometrically at a $1: 2.5$ ratio of soil to $0.01 \mathrm{M} \mathrm{CaCl}_{2}$ after $1 \mathrm{~h}$ of end-to-end shaking. Carbonate content was measured using the acid neutralization method (Allison and Moodie, 1965). The content of soil organic carbon (SOC) was determined using the acid dichromate oxidation method described by Nelson and Sommers (1982).

Cation exchange capacity (CEC) of soil was determined by $\mathrm{NH}_{4}^{+}$retention after percolation with a solution of $1 \mathrm{M} \mathrm{NH}_{4} \mathrm{OAc}$ ( $\mathrm{pH}$ 7.0) (Chapman, 1965). Amorphous and crystalline $\mathrm{Al}$ and $\mathrm{Fe}$ hydroxides were extracted by $\mathrm{NH}_{4}^{+}$-oxalate (Schwertmann, 1964) and by dithionitecitrate-bicarbonate (DCB) (Mehra and Jackson, 1960), respectively. Iron and $\mathrm{Al}$ in the extracts were analyzed using inductively coupled plasma atomic emission spectrometry (ICP-AES). The background concentrations of As in soil was determined by ICP-AES or inductively coupled plasma mass spectrometry (ICP-MS) after the uncontaminated soil samples $(<0.25 \mathrm{~mm})$ were digested with aqua regia and hydrofluoric acid.

\subsection{Procedure for the physiologically based in vitro test}

The physiologically based extraction test proposed by Ruby et al. (1996) was employed with some modifications derived basically from the in vitro model proposed by Rodriguez et al. (1999). Full details of the in vitro test procedure are described in Tang et al. (2006); only brief details are given here. The test, including the gastric $(\mathrm{pH} 1.5,1 \mathrm{~h}$, $37^{\circ} \mathrm{C}$ ) and small intestinal phases $\left(\mathrm{pH} 7,4 \mathrm{~h}, 37^{\circ} \mathrm{C}\right)$, was conducted with $6 \mathrm{~g}$ of soil in $600 \mathrm{ml}$ of synthetic digestive juice (mainly composed of $\mathrm{NaCl}$, organic acids, and enzymes) under anaerobic conditions. Constant mixing was performed using paddle stirrers at a speed of approximately $100 \mathrm{rpm}$.

After each phase, $20 \mathrm{ml}$ of suspension sample was collected using a syringe and centrifuged at $7000 \mathrm{~g}$ for $10 \mathrm{~min}$ before filtering the supernatant through a $0.45 \mu \mathrm{m}$ cellulose nitrate filter.

All in vitro tests were performed in duplicate for each soil sample, including both controls and As-amended samples. Soluble As contents in the artificial digests were analyzed with ICP-AES or ICP-MS.

\subsection{Procedure for the sequential extraction of soil As}

An improved sequential extraction proposed by Wenzel et al. (2001) was adopted for this study. Soil $(1 \mathrm{~g})$ was extracted sequentially with $25 \mathrm{ml}$ of $\left(\mathrm{NH}_{4}\right)_{2} \mathrm{SO}_{4}(0.05 \mathrm{M})$, $\left(\mathrm{NH}_{4}\right)_{2} \mathrm{H}_{2} \mathrm{PO}_{4}(0.05 \mathrm{M}), \mathrm{NH}_{4}$-oxalate $(0.2 \mathrm{M})$, and $\mathrm{NH}_{4^{-}}$ oxalate $(0.2 \mathrm{M})$-ascorbic acid $(0.1 \mathrm{M})$, and finally with aqua regia and perchloric acid. The five sequential extraction steps were assumed to correspond respectively to non-specifically sorbed As (F1), specifically sorbed As
(F2), As associated with amorphous and poorly-crystalline hydrous oxides of Fe and Al (F3), As associated with wellcrystallized hydrous oxides of $\mathrm{Fe}$ and $\mathrm{Al}(\mathrm{F} 4)$, and residual As (F5). A standard reference soil GSS-1 (National Research Center for Geoanalysis, Beijing, China) was used for quality control of the acid digestion and instrument performance. The recovery for As in the standard reference soil GSS-1 was 98.4\%.

Extracts were filtered through $0.45 \mu \mathrm{m}$ cellulose nitrate filters prior to As analysis. All extractions were performed in duplicate and included determinations on both control and As-amended soils. The overall recovery of As using the fractionation procedure, as determined by comparing the sum of As determined in all five fractions with a single total As determination, was found to be within the range of 92.9-105.9\%.

\subsection{Statistical analysis}

Statistical analysis was carried out using SPSS for Windows. Statistically significant differences in As concentration in an individual soil fraction between different incubation times ( 7 points) for each soil, or between unpolluted (5 points, d 120 samples) or polluted (5 points, d 120 samples) soils were analyzed using analysis of variance (ANOVA) and Least Significant Difference (LSD) at a $5 \%$ significance level. The same statistical analysis was carried out to reveal the effect of incubation time on As bioaccessibility in both the gastric and small intestinal phases for each soil. Correlation analysis was performed to identify significant positive or negative relationships between individual or combined As fraction(s) and As bioaccessibility at different incubation times for each soil, as well as between As bioaccessibility (at d 120) and soil properties or As fraction(s) (at d 120) of different soils. Multivariable linear regression was used to identify the significant soil properties affecting As bioaccessibility under steady state conditions.

\section{Results and discussion}

\subsection{Effect of ageing on the distribution of As between different soil fractions}

The statistical significance of changes in As concentrations in individual soil fractions with increasing incubation time was examined using ANOVA and LSD procedures. For all soils studied, the results show that even at the first sampling (d 1), the addition of As had resulted in increased As concentrations in all five soil fractions (Table 2). However, it is also clear from the data shown in Fig. 1, that some redistribution of As between fractions took place during the ensuing incubation. This is also emphasized by the changes in As concentrations in the different fractions between $\mathrm{d} 1$ and the end of the study at d 120 (Table 2).

The results show that for three of the soils $(\mathrm{CC}, \mathrm{BJ}$ and $\mathrm{NJ})$, the F1 fraction decreased markedly within the first 
Table 2

As concentrations in individual soil fractions of unpolluted and As-amended soils ${ }^{\mathrm{a}}$

\begin{tabular}{|c|c|c|c|c|c|}
\hline \multirow[t]{2}{*}{ Soil } & \multicolumn{5}{|c|}{ As concentrations in individual soil fractions $\left(\mathrm{mg} \mathrm{kg}^{-1}\right)$} \\
\hline & $\mathrm{F} 1$ & $\mathrm{~F} 2$ & F3 & F4 & F5 \\
\hline \multicolumn{6}{|l|}{$C C$} \\
\hline Unpolluted & $0.03 \pm 0.01$ & $0.83 \pm 0.04$ & $3.91 \pm 0.16$ & $2.27 \pm 0.12$ & $3.62 \pm 0.13$ \\
\hline As-amended (d 1) & $11.65 \pm 1.00 \mathrm{a}$ & $69.44 \pm 1.96 \mathrm{a}$ & $41.08 \pm 1.38 b$ & $5.18 \pm 0.53 b$ & $16.76 \pm 0.69 b$ \\
\hline As-amended (d 120) & $5.66 \pm 0.22 b$ & $61.84 \pm 1.16 b$ & $47.55 \pm 1.98 \mathrm{a}$ & $8.03 \pm 0.44 \mathrm{a}$ & $19.12 \pm 0.79 \mathrm{a}$ \\
\hline \multicolumn{6}{|l|}{$B J$} \\
\hline Unpolluted & $0.27 \pm 0.03$ & $0.81 \pm 0.02$ & $3.03 \pm 0.17$ & $4.81 \pm 0.05$ & $2.73 \pm 0.06$ \\
\hline As-amended (d 1) & $49.08 \pm 0.53 \mathrm{a}$ & $52.76 \pm 1.24 \mathrm{a}$ & $27.19 \pm 1.58 b$ & $9.51 \pm 0.26 b$ & $8.96 \pm 0.26 b$ \\
\hline As-amended (d 120) & $30.04 \pm 2.78 b$ & $52.93 \pm 2.44 \mathrm{a}$ & $33.58 \pm 1.39 \mathrm{a}$ & $10.59 \pm 0.28 \mathrm{a}$ & $17.97 \pm 1.11 \mathrm{a}$ \\
\hline \multicolumn{6}{|l|}{$N J$} \\
\hline Unpolluted & $0.05 \pm 0.01$ & $0.59 \pm 0.05$ & $3.18 \pm 0.17$ & $2.63 \pm 0.07$ & $2.25 \pm 0.10$ \\
\hline As-amended (d 1) & $18.32 \pm 1.12 \mathrm{a}$ & $78.15 \pm 2.28 \mathrm{a}$ & $43.26 \pm 1.05 b$ & $5.46 \pm 0.60 b$ & $6.31 \pm 0.27 b$ \\
\hline As-amended (d 120) & $12.15 \pm 1.19 b$ & $68.63 \pm 1.16 b$ & $49.88 \pm 1.33 \mathrm{a}$ & $8.84 \pm 0.34 \mathrm{a}$ & $8.90 \pm 0.27 \mathrm{a}$ \\
\hline \multicolumn{6}{|l|}{$Y J$} \\
\hline Unpolluted & $0.009 \pm 0.001$ & $0.90 \pm 0.05$ & $3.60 \pm 0.02$ & $6.83 \pm 0.07$ & $9.17 \pm 0.09$ \\
\hline As-amended (d 1) & $1.38 \pm 0.06 \mathrm{a}$ & $52.07 \pm 2.87 \mathrm{a}$ & $48.03 \pm 1.53 b$ & $30.44 \pm 0.19 b$ & $20.69 \pm 0.47 b$ \\
\hline As-amended (d 120) & $0.54 \pm 0.07 b$ & $44.24 \pm 1.70 b$ & $52.42 \pm 1.54 \mathrm{a}$ & $31.86 \pm 0.87 \mathrm{a}$ & $22.64 \pm 0.25 \mathrm{a}$ \\
\hline \multicolumn{6}{|l|}{$H N$} \\
\hline Unpolluted & $0.004 \pm 0.001$ & $0.41 \pm 0.04$ & $1.50 \pm 0.12$ & $4.78 \pm 0.21$ & $10.95 \pm 0.55$ \\
\hline As-amended (d 1) & $1.25 \pm 0.03 \mathrm{a}$ & $46.18 \pm 1.30 \mathrm{a}$ & $39.39 \pm 0.92 \mathrm{a}$ & $26.05 \pm 0.63 b$ & $35.02 \pm 1.72 b$ \\
\hline As-amended (d 120) & $0.51 \pm 0.13 b$ & $38.89 \pm 0.16 b$ & $38.30 \pm 0.13 \mathrm{a}$ & $27.79 \pm 0.29 \mathrm{a}$ & $43.00 \pm 0.95 a$ \\
\hline
\end{tabular}

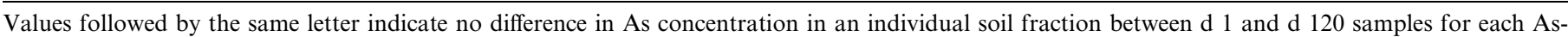
mended soil at $P<0.05$.

a Mean \pm standard deviation.

month following the As addition $(P<0.05)$. This fraction is assumed to consist of easily exchangeable, outer-sphere complexes of As (Wenzel et al., 2001). In the case of the YJ and HN soils, very little of the added As appeared in this fraction, even at d 1 (Table 2). However, even with these soils, although difficult to see in Fig. 1, there was a decrease in the proportion of As associated with this fraction during the first week of the incubation $(P<0.05)$.

With the exception of the BJ soil, decreases in the F2 fraction were also observed during the incubation $(P<0.05)$. The decreases occurred generally faster (within one week) for the YJ and HN soils compared with the $\mathrm{CC}$ and $\mathrm{NJ}$ soils (within one month). According to Wenzel et al. (2001), $\left(\mathrm{NH}_{4}\right)_{2} \mathrm{H}_{2} \mathrm{PO}_{4}$ extracts varied proportions of inner-sphere surface complexes of As, depending on the ionic strength of the solution.

In contrast to the first two fractions, the proportions of As in the $\mathrm{F} 3$ fraction generally increased during the incubation $(P<0.05)$. An exception occurred with the HN soil, which showed a small but no significant decrease in this fraction during the incubation (Table 2). There were again differences in the rates at which the changes occurred with the proportion of As in the F3 fraction increasing more slowly with the $\mathrm{CC}, \mathrm{BJ}$ and $\mathrm{NJ}$ soils compared with the $\mathrm{YJ}$ soil. However, for all soils, the $\mathrm{F} 3$ fraction was stable after one month.

The proportions of As in the F4 fraction increased during the incubation but were generally stable within the first 1-2 weeks $(P<0.05)$. The $\mathrm{F} 5$ fraction also increased for all five soils during the incubation. However, the increases were generally complete within the first week of incubation, and the proportions of As associated with the residual fraction remained stable after this period.

In summary, there were clear changes in the proportional distribution of As in all five soils during the first month of incubation after As addition. The proportions of As associated with the most weakly bound fractions (F1 and F2) tended to decrease, with corresponding increases in the other three more strongly binding fractions (F3, F4 and F5). There were differences in the rates at which redistribution took place with the changes occurring faster in the YJ and HN soils compared with the other three soils. This is most probably due to the acidic nature of the YJ and HN soils, and their much higher $\mathrm{Fe}$ and $\mathrm{Al}$ contents (Table 1).

\subsection{Comparison of As fractionation in unpolluted and As-amended soils}

A comparison between native soil As distribution (unpolluted soils), and the distribution of applied As between fractions using ANOVA and LSD analysis is shown in Table 3. There are clearly some major differences $(P<0.05)$ between the native and applied As distributions, but there are also differences $(P<0.05)$ between some of the individual soils. In the case of the native soil As, the proportions present in the F1 and F2 fractions were very low for all soils, with the bulk of the As distributed between the F3, F4 and F5 fractions. In the case of the YJ and HN soils, between $80 \%$ and $90 \%$ of the total As occurs in the F4 and $\mathrm{F} 5$ fractions, with much smaller proportions present in 

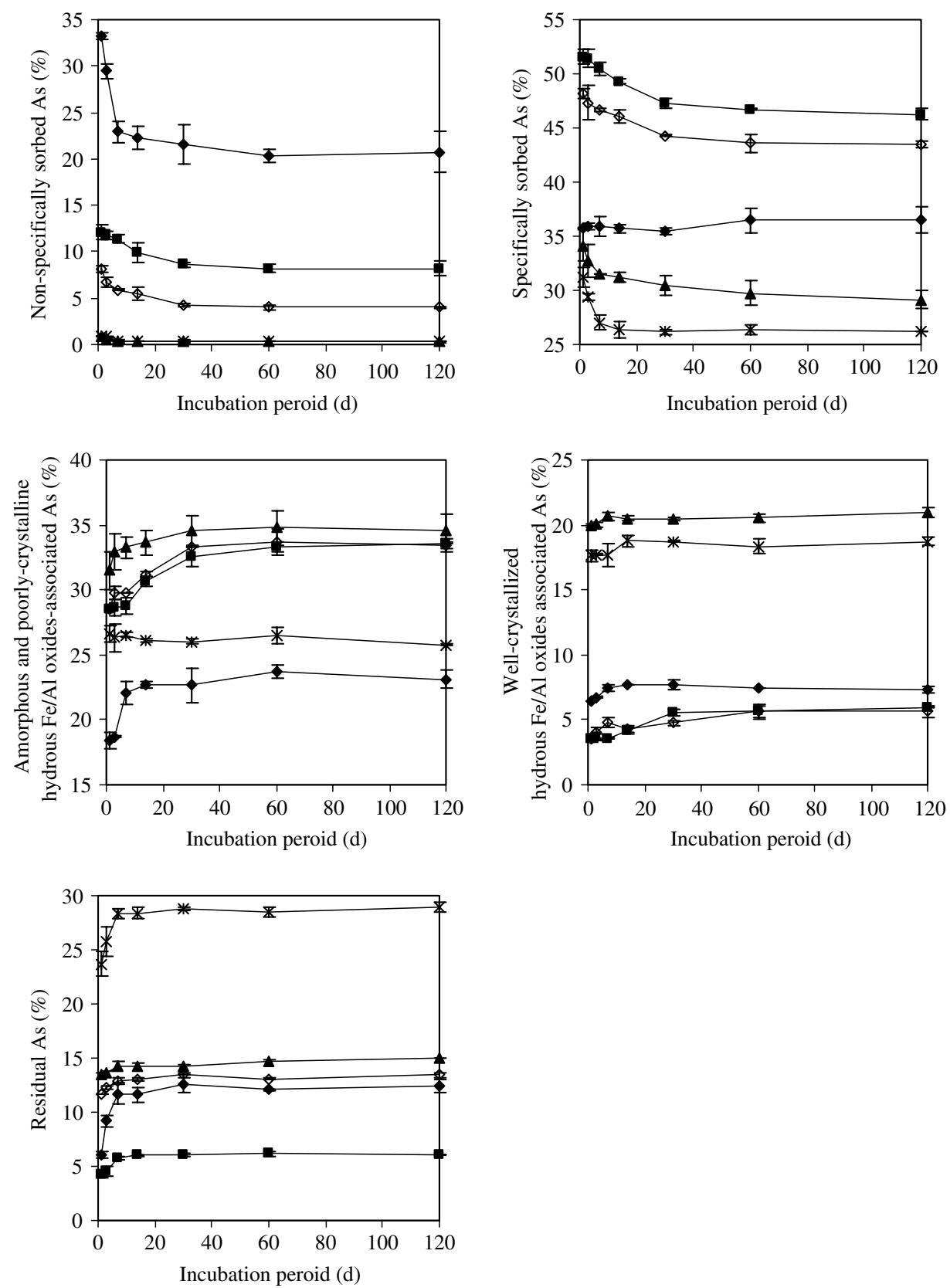

Fig. 1. The variation of As fractionation in soils during the ageing process $(\diamond$, Mean \pm standard deviation).

the F3 fraction (Table 3). This no doubt reflects the very high concentrations of crystalline $\mathrm{Fe}$ and $\mathrm{Al}$ oxides in the YJ and HN compared with the other soils (Table 1).

In general, the distribution pattern of the added As was substantially different from that of the indigenous As, with the As tending to be more labile. The proportions of added As in the F1 fraction were consistently higher than for the native soil As $(P<0.05)$ (Table 3$)$. However, for the YJ and $\mathrm{HN}$ soils the proportions present in this fraction were still less than $1 \%$ of the total added As. For all soils, the greatest proportions of added As appeared in the F2, F3 and F4 fractions. However, the distribution of As in the $\mathrm{YJ}$ and $\mathrm{HN}$ soils were again somewhat different than in the other soils, with substantially higher proportions of added As present in the F4 and F5 fractions (Table 3). As noted above, this reflects the much higher concentration of $\mathrm{Fe}$ and $\mathrm{Al}$ in these two soils and probably also their much lower $\mathrm{pH}$ values. The formation of a variety of inner-sphere surface complexes of arsenate with $\mathrm{Fe}$ oxides has been observed in spectroscopic studies (Waychunas et al., 1993; Fendorf et al., 1997).

\subsection{The effect of ageing on As bioaccessibility in soils}

It was observed during the first 1-2 weeks of incubation, that the bioaccessibility of As in all soils decreased 
Table 3

Proportional distribution of native and applied As in soils $\mathrm{s}^{\mathrm{a}}$

\begin{tabular}{|c|c|c|c|c|c|}
\hline \multirow[t]{2}{*}{ Soil } & \multicolumn{5}{|c|}{ Proportions of As in individual soil fractions (\%) } \\
\hline & $\overline{\mathrm{F} 1}$ & $\mathrm{~F} 2$ & F3 & $\mathrm{F} 4$ & F5 \\
\hline \multicolumn{6}{|l|}{ Native $A s^{\mathrm{b}}$} \\
\hline BJ & $2.33 \pm 0.18 \mathrm{aB}$ & $6.92 \pm 0.06 \mathrm{bB}$ & $26.03 \pm 1.01 \mathrm{bA}$ & $41.31 \pm 0.34 \mathrm{aA}$ & $23.41 \pm 0.92 \mathrm{dA}$ \\
\hline NJ & $0.63 \pm 0.09 \mathrm{bB}$ & $6.78 \pm 0.58 \mathrm{bB}$ & $36.54 \pm 2.18 \mathrm{aA}$ & $30.21 \pm 0.64 \mathrm{cA}$ & $25.84 \pm 1.05 \mathrm{dA}$ \\
\hline YJ & $0.04 \pm 0.01 \mathrm{cB}$ & $4.39 \pm 0.24 \mathrm{cB}$ & $17.55 \pm 0.04 \mathrm{cB}$ & $33.32 \pm 0.27 \mathrm{bA}$ & 44. $70 \pm 0.54 \mathrm{bA}$ \\
\hline $\mathrm{HN}$ & $0.02 \pm 0.00 \mathrm{cB}$ & $2.32 \pm 0.27 \mathrm{~dB}$ & $8.48 \pm 0.46 \mathrm{~dB}$ & $27.13 \pm 1.84 \mathrm{dA}$ & $62.06 \pm 1.64 \mathrm{aA}$ \\
\hline \multicolumn{6}{|l|}{ Applied $A s^{\mathrm{c}}$} \\
\hline $\mathrm{CC}$ & $4.28 \pm 0.05 \mathrm{cA}$ & $46.39 \pm 0.43 \mathrm{bA}$ & $33.17 \pm 0.91 \mathrm{bB}$ & $4.38 \pm 0.46 \mathrm{cB}$ & $11.78 \pm 0.27 \mathrm{bB}$ \\
\hline BJ & $22.32 \pm 2.40 \mathrm{aA}$ & $39.05 \pm 1.28 \mathrm{cA}$ & $22.89 \pm 0.72 \mathrm{~dB}$ & $4.33 \pm 0.27 \mathrm{cB}$ & $11.42 \pm 0.67 \mathrm{bB}$ \\
\hline NJ & $8.65 \pm 0.59 \mathrm{bA}$ & $48.71 \pm 0.67 \mathrm{aA}$ & $33.43 \pm 0.07 \mathrm{bB}$ & $4.45 \pm 0.11 \mathrm{cB}$ & 4. $76 \pm 0.04 \mathrm{~dB}$ \\
\hline YJ & $0.40 \pm 0.05 \mathrm{dA}$ & $33.03 \pm 0.96 \mathrm{dA}$ & $37.21 \pm 1.56 \mathrm{aA}$ & $19.08 \pm 0.46 \mathrm{aB}$ & $10.27 \pm 0.09 \mathrm{cB}$ \\
\hline $\mathrm{HN}$ & $0.39 \pm 0.10 \mathrm{dA}$ & $29.40 \pm 0.06 \mathrm{eA}$ & $28.13 \pm 0.08 \mathrm{cA}$ & $17.59 \pm 0.34 \mathrm{bB}$ & $24.49 \pm 0.57 \mathrm{aB}$ \\
\hline
\end{tabular}

Values followed by the same lowercase indicate no difference in the concentration of native (or applied) As in an individual soil fraction between different soils, while values followed by the same uppercase denote no difference between native and applied As concentration in an individual fraction for an individual soil, at $P<0.05$.

${ }^{\mathrm{a}}$ Mean \pm standard deviation.

b Unpolluted soils.

${ }^{\mathrm{c}}$ Calculated by the difference between unpolluted soils and As-amended soils at d 120 .

exponentially to a relatively stable level, for both the gastric and small intestinal phases (Fig. 2). Generally, the decrease in bioaccessibility occurred faster in the acid, high Fe soils ( $\mathrm{YJ}$ and $\mathrm{HN}$ ) compared with the soils with higher $\mathrm{pH}$ vales and lower Fe contents (CC, BJ and $\mathrm{NJ}$ ). At the steady state, the bioaccessibility of As in the more acidic soils ( $\mathrm{YJ}$ and $\mathrm{HN}$ ) was also substantially lower than that in the other soils, in both the gastric and small intestinal phases (Fig. 2). In agreement with other researchers (Ruby et al., 1996; Rodriguez et al., 1999; Ellickson et al., 2001), only slight differences were observed in the bioaccessibility of As between the gastric and intestinal phases for each soil (As bioaccessibility between gastric and instestinal phases significantly different $(P<0.05)$ for 18 out of 35 pairs).

Yang et al. (2002) found that DCB-extractable Fe oxide was the most important soil property controlling the initial degree of adsorption of As added to soil. In the present study, soil $\mathrm{pH}$ was found to be the most important factor governing the bioaccessibility (at d 120) of As in both the gastric and small intestinal phases. Pearson's correlation coefficients for the relationships between soil $\mathrm{pH}$ and As bioaccessibility were $0.923(P<0.05)$ and $0.966(P<0.01)$ for the gastric and small intestinal phases. Yang et al. (2002) developed a multivariable regression model, including soil $\mathrm{pH}$ and $\mathrm{Fe}$ oxide content as variables, which was able to explain nearly $75 \%$ of the variability in arsenate bioaccessibility in the gastric phase. In the present study, As bioaccessibility in both the gastric and small intestinal phases were marginally related (negatively) to both DCBextractable $\mathrm{Fe}$ oxide concentrations $(P=0.053$ and 0.053 , one-tailed) and its logarithm $(P=0.028$ and 0.026 , one tailed). However, the relationships between As accessibility
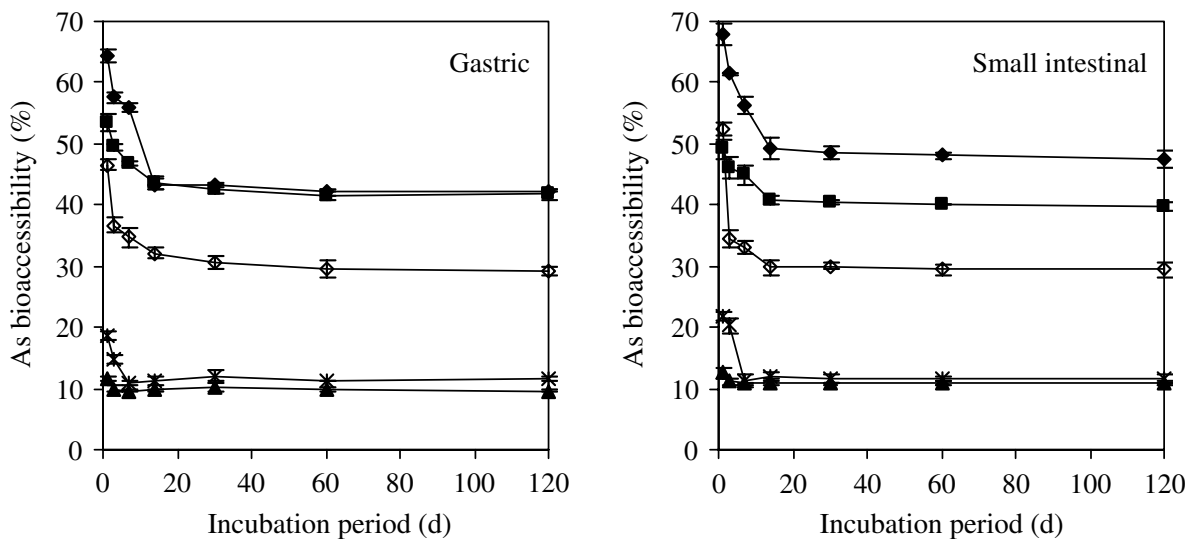

Fig. 2. The variation of As bioaccessibility in soils during the ageing process in both the gastric and small intestinal phases $(\diamond, \diamond, \mathbf{\square}, \mathbf{\Delta}$ and $*$ represent the $\mathrm{CC}, \mathrm{BJ}, \mathrm{NJ}, \mathrm{YJ}$ and $\mathrm{HN}$ soils, respectively. Mean \pm standard deviation). 
and $\mathrm{pH}$ were not significantly improved by using multiple linear regression incorporating a term for $\mathrm{Fe}$ oxides.

The bioaccessibility of As in the unpolluted soils ranged from $2.5 \%$ to $7.9 \%$ in the gastric phase, and from $2.7 \%$ to $9.1 \%$ in the small intestinal phase, and was much lower than that in the artificially polluted soils $(9.7-42.3 \%$ in the gastric phase and $10.9-47.4 \%$ in the small intestinal phase). These observations suggest that As artificially added to soils is much more labile and bioaccessible than native soil As and thus poses a greater health risk to humans. However, this is confounded by the higher amounts of As present in the contaminated soils $\left(144.2-155.6 \mathrm{mg} \mathrm{kg}^{-1}\right)$ compared to $9.4-20.8 \mathrm{mg} \mathrm{kg}^{-1}$ in the uncontaminated soils. In fact, it is possible to explain a high degree of the variation in As bioaccessibility across both uncontaminated and contaminated soils by means of multiple regression models that include terms for both soil $\mathrm{pH}$ and total soil As content. In the case of the gastric phase, $79.0 \%$ of the variability in As bioaccessibility is explained by Eq. (1)

As bioaccessibility $=7.25 \mathrm{pH}+0.158$ total As

$$
-38.9(P<0.01)
$$

For the small intestinal phase, $81.6 \%$ of the variability in As bioaccessibility is explained by Eq. (2)

As bioaccessibility $=8.02 \mathrm{pH}+0.162$ total As

$$
-42.4(P<0.01)
$$

\subsection{The relationship between As fractionation and bioaccessibility}

Correlations between As bioaccessibility and single or combined soil As fractions, throughout the whole incubation period for each individual soil, were determined in an attempt to reveal the possible sources of As available for intestinal absorption (Table 4). There were positive significant $(P<0.05$ or $P<0.01)$ relationships between As in the F1 fraction and As bioaccessibility in both the gastric and small intestinal phases for all five soils. Except for the BJ soil, As bioaccessibility in either the gastric or small intestinal phase was also positively and significantly $(P<0.05$ or $P<0.01)$ related to $\mathrm{As}$ in the $\mathrm{F} 2$ fraction. In contrast, except for the HN soil, negative significant relationships $(P<0.05$ or $P<0.01)$ were observed between As bioaccessibility and As in the F3 fraction. Arsenic bioaccessibility was also negatively related, highly significantly, to As in the F4 and F5 fractions.

The significant correlations observed between As in the F1 (and F2) fraction(s) and As bioaccessibility indicates that non-specifically and specifically sorbed As are likely to constitute the main proportions of bioaccessible As. The ageing process is assumed to be initiated by a gradual shift from the rapid formation of out-sphere (electrostatic) complexes to inner-sphere (chemical) complexes with increasing reaction time (Zhang and Sparks, 1990). Thus, the ageing process, involving a shift from outer-sphere As complexes to inner-sphere As, and then gradually to even less labile fractions including F3, F4 and F5 will result in a decrease in As bioaccessibility. Fendorf et al. (2004) have also reported an exponential decrease in As bioaccessibility through the first $100 \mathrm{~d}$ of incubation, accompanied by a highly correlated decrease in exchangeable As.

An additional correlation analysis was also performed between the sequentially extracted As fraction(s) and bioaccessible As across all the experimental soils for the data obtained at the final sampling, i.e. after four months of incubation (Table 5). The results show that As bioaccessibility was significantly correlated $(P<0.01)$ with the sum of As in F1 plus F2 fractions. Moreover, for all five soils, the amount of bioaccessible As was found to be greater

Table 5

Pearson's correlation coefficients between sequentially extracted As fraction(s) and As bioaccessibility in both the gastric and small intestinal phases across five studied soils under nearly stable conditions after 4 months of incubation

\begin{tabular}{lcc}
\hline & \multicolumn{2}{c}{ Bioaccessibility } \\
\cline { 2 - 3 } & Gastric & Small intestinal \\
\hline F1 & 0.820 & $0.896^{*}$ \\
F2 & 0.810 & 0.731 \\
F1+F2 & $0.987^{* *}$ & $0.984^{* *}$ \\
F3 & 0.174 & 0.275 \\
F4 & $-0.912^{*}$ & -0.876 \\
F5 & -0.639 & -0.607 \\
\hline
\end{tabular}

${ }^{*}$ and ${ }^{* *}$ represent $5 \%$ and $1 \%$ levels of significance (two-tailed), respectively.

Table 4

Pearson's correlation coefficients between each sequentially extracted As fraction and As bioaccessibility in both the gastric and small intestinal phases for

\begin{tabular}{|c|c|c|c|c|c|c|c|c|c|c|}
\hline & \multicolumn{10}{|c|}{ Bioaccessibility } \\
\hline & \multicolumn{2}{|l|}{$\mathrm{CC}$} & \multicolumn{2}{|l|}{ BJ } & \multicolumn{2}{|l|}{ NJ } & \multicolumn{2}{|l|}{ YJ } & \multicolumn{2}{|l|}{$\mathrm{HN}$} \\
\hline & Gastric & Small intestinal & Gatric & Small intestinal & Gastric & Small intestinal & Gastric & Small intestinal & Gastric & Small intestinal \\
\hline F1 & $0.958^{* *}$ & $0.860^{*}$ & $0.908^{* *}$ & $0.967^{* *}$ & $0.932^{* *}$ & $0.938^{* *}$ & $0.932^{* *}$ & $0.971^{* *}$ & $0.904^{* *}$ & $0.990^{* *}$ \\
\hline $\mathrm{F} 2$ & $0.884^{* *}$ & 0.744 & -0.277 & -0.263 & $0.913^{* *}$ & $0.910^{* *}$ & 0.742 & $0.808^{*}$ & $0.954^{* *}$ & $0.968^{* *}$ \\
\hline F3 & $-0.881^{* *}$ & -0.747 & $-0.905^{* *}$ & $-0.955^{* *}$ & $-0.882^{* *}$ & $-0.892^{* *}$ & $-0.770^{*}$ & $-0.850^{*}$ & 0.402 & 0.418 \\
\hline $\mathrm{F} 4$ & $-0.826^{*}$ & -0.706 & $-0.835^{*}$ & $-0.898^{* *}$ & $-0.826^{*}$ & $-0.829^{*}$ & -0.726 & -0.746 & -0.600 & -0.692 \\
\hline F5 & $-0.957^{* *}$ & $-0.903^{* *}$ & $-0.871^{*}$ & $-0.938^{* *}$ & $-0.947^{* *}$ & $-0.917^{* *}$ & -0.673 & $-0.719^{*}$ & $-0.967^{* *}$ & $-0.970^{* *}$ \\
\hline
\end{tabular}
each soil through the whole incubation time

${ }^{*}$ and ${ }^{* *}$ represent $5 \%$ and $1 \%$ levels of significance (two-tailed), respectively. 
than As in the F1 fraction but lower than in the sum of As in F1 and F2 fractions. Since in this study, only five soil samples, though representing the major soil types in China, were included, it is desirable that future studies using soils from a larger number of sites with different contamination history should be conducted.

\section{Acknowledgements}

The authors would like to thank the financial support from the National Foundation of Natural Science of China (Grant Nos. 40321101, 40225002 and 40235054), the Japan Society for the Promotion of Science (P 04575).

\section{References}

Allison, L.E., Moodie, C.D., 1965. Carbonate. In: Black, C.A. (Ed.), Methods of Soil Analysis. Part II. Am. Soc. Agron., Madison, Wisconsin, pp. 1379-1396.

Axe, L., Trivedi, P., 2002. Intraparticle surface diffusion of metal contaminants and their attenuation in microporous amorphous $\mathrm{Al}$, Fe, and Mn oxides. J. Colloid Interf. Sci 247, 259-265.

Calabrese, E.J., Stanek, E.J., 1995. Resolving inter-tracer inconsistencies in soil ingestion estimation. Environ. Health Perspect. 103, 454- 457.

Chapman, H.D., 1965. Cation-exchange capacity. In: Black, C.A. (Ed.), Methods of soil analysis. Part II. Amer. Soc. Agron., Madison, WI, USA, pp. 891-901.

Cooperative Research Group on Chinese Soil Taxonomy, 2001. Chinese Soil Taxonomy. Science Press, Beijing, China.

Duggan, M.J., Inskip, M.J., Rundle, S.A., Moorcroft, J.S., 1985. Lead in playground dust and on the hands of schoolchildren. Sci. Total Environ. 44, 65-79.

Ellickson, K.M., Meeker, R.J., Gallo, M.A., Buckley, B.T., Lioy, P.J., 2001. Oral bioavailability of lead and arsenic from a NIST standard reference soil material. Arch. Environ. Contam. Toxicol. 40, 128135

Fendorf, S., Eick, M.J., Grossl, P., Sparks, D.L., 1997. Arsenate and chromate retention mechanisms on goethite. 1. surface structure. Environ. Sci. Technol. 31, 315-320.

Fendorf, S., Force, M.J.L., Li, G., 2004. Temporal changes in soil partitioning and bioaccessibility of arsenic, chromium, and lead. J. Environ. Qual. 33, 2049-2055.

Ford, R.G., Sparks, D.L., 2000. The nature of $\mathrm{Zn}$ precipitates formed in the presence of pyrophylite. Environ. Sci. Technol. 34, 2479-2483.

Hayes, K.F., Leckie, J.O., 1986. Mechanism of lead ion adsorption at the goethite-water interface. In: Davis, J.A., Hayes, K.F. (Eds.), Geo- chemical processes at mineral surfaces, ACS Symp. Ser. 323 Am.Chem.Soc., Washington, DC, pp. 114-141.

Lu, R.K., 2000. Analytical methods for soils and agricultural chemistry. China Agricultural Science and Technology Press, Beijing, China.

Mehra, O.P., Jackson, M.L., 1960. Iron oxide removal from soils and clays by a dithionitecitrate system buffered with sodium-bicarbonate. Clay Clay Miner. 7, 317-327.

Miller, D.D., Schricker, B.R., 1981. In vitro estimation of food iron bioavailability. Am. J. Clin. Nutrit. 34, 2248-2256.

Nelson, D.W., Sommers, L.E., 1982. Total carbon, organic carbon, and organic matter. In: Page, A.L., Miller, R.H., Keeney, D.R. (Eds.), Methods of soil analysis (Part 2, Chemical and Microbiological Properties). Amer. Soc. Agron. Soil Sci. Soc. Amer., Madison, WI, USA, pp. 539-579.

Rodriguez, R.R., Basta, N.T., Casteel, S.W., Pace, L.W., 1999. An in vitro gastrointestinal method to estimate bioavailable arsenic in contaminated soils and solid media. Environ. Sci. Technol. 33, 642-649.

Ruby, M.V., Davis, A., Schoof, R., Eberle, S., Sellstone, C.M., 1996. Estimation of lead and arsenic bioavailability using a physiological based extraction test. Environ. Sci. Technol. 30, 422-430.

Ruby, M.V., Schoof, R., Brattin, W., Goldade, M., Post, G., Harnois, M., Mosby, D.E., Casteel, S.W., Berti, W., Carpentier, M., Edwards, D., Cragin, D., Chappel, W., 1999. Advances in evaluating the oral bioavailability of inorganics in soil for use in human health risk assessment. Environ. Sci. Technol. 33, 3697-3705.

Schwertmann, U., 1964. Differenzierung der Eisenoxide des Bodens durch Extraktion mit ammoniumoxalat-lösung. Z. Pflanzenernähr. Bodenkd. 105, 194-202.

Tang, X.Y., Zhu, Y.G., Cui, Y.S., Duan, J., Tang, L., 2006. The effect of ageing on the bioaccessibility and fractionation of cadmium in some typical soils of China. Environ. Int. 32, 682-689.

Van Wijnen, J.H., Clausing, P., Brunekreef, B., 1990. Estimated soil ingestion by children. Environ. Res. 51, 147-162.

Waychunas, G.A., Rea, B.A., Fuller, C.C., Davis, J.A., 1993. Surface chemistry of ferrihydrite: Part 1. EXAFS studies of the geometry of coprecipitated and adsorbed arsenate. Geochim. Cosmochim. Acta. 57, 2251-2269.

Wenzel, W.W., Kirchbaumer, N., Prohaska, T., Stingeder, G., Lombi, E., Adriano, D.C., 2001. Arsenic fractionation in soils using an improved sequential extraction procedure. Anal. Chim. Acta. 436, 309-323.

Yang, J., Varnet, M.O., Basta, P.M., Jardine, N.T., Casteel, S.W., 2002. Adsorption, sequestration, and bioaccessibility of $\mathrm{As}(\mathrm{V})$ in soils. Environ. Sci. Technol. 36, 4562-4569.

Yang, J., Barnett, M.O., Zhuang, J., Fendorf, S.E., Jardine, P.M., 2005. Adsorption, oxidation, and bioaccessibility of As(III) in soils. Environ. Sci. Technol. 39, 7102-7110.

Zhang, P.C., Sparks, D.L., 1990. Kinetics selenite and selenate adsorption/desorption at the goethite/water interface using pressure-jump relaxation. Environ. Sci. Technol. 24, 1848-1856. 